primary derangement of the vaso-motor centre. The latter, notwithstanding the arguments which have been brought against it, seems the more probable. I would suggest that a similar explanation may be given of chorea. That the primary change affects the vaso-motor centre, or centres, and that the muscular movements are due to secondary vascular disturbance interfering with the nutrition of the cortical cells-recent physiology points to the cortex cerebri, not to the corpus striatum as affected in chorea,--thereby rendering them liable to take an abnormal and, as it were, independent action (a predisposition in this direction being assumed); and that, on this hypothesis, all the other symptoms of chorea admit of harmonious explanation is, I think, rendered probable by the following considerations:-

1. As regards the cardicuc phenomena of chorea. Irregularity and acceleration of the heart's action are better explained on the assumption of deranged innervation than by referring them to some morbid cardiac condition, of which there is no evidence. That a cardiac murmur can be referred to the same source has been denied, although its occurrence in such a disease as exophthalmic goitre can hardly be explained on any other hypothesis. Assuming, however, that cardiac innervation is in some way disturbed in chorea-and early irregularity at least points in that direction, - there is another element present, hitherto, so far as I am aware, unnoticed, which makes the occurrence of a murmur extremely likely. Chorea is a disease mainly of that period of life when the body itself is in a state of growth. In this the heart, like all other organs, shares; but unlike other organs (with the exception of the blood vessels and the brain), the growth of the various parts of the heart does not proceed pari passu. The increase in weight is mainly confined to the ventricles, for the auricles lose in proportion to the ventricles up to the period of completed development of the adolescent, ${ }^{12}$ and it is during this very period that chorea mainly occurs; and though it occurs after adolescence, the heart is then rarely affected. That the great strain thrown utpon the left ventricle by the excessive muscular movements of chorea, along with irregular arterial action in the cerebral circulation, should result in occasional regurgitation and the development of a murmur seems not improbable.

2. The respiratory phenomena of chorea.-Little attention has been paid to the respiratory symptoms which all admit to occur in chorea. They cannot in every case be referred to irregular action of the thoracic respiratory muscles. It is much more probable that they, too, are dependent upon deranged innervation, the diaphragm being immediately affected; and as the respiratory centre is closely connected with that which controls the heart and bloodvessels, there is in and around the vaso-motor centre in the medulla oblongata a focus, interference with which may directly occasion the cardiac and respiratory, and indirectly the motor and other, phenomena of chorea.

3. Cessation of choreic movements during sleep. - This feature is eminently characteristic of chorea, being, in fact, rarely absent. That some change affects the cerebral circulation prior to the supervention of sleep is certain; that this change is closely connected with a variation in the blood-pressure is highly probable. One may well suppose that the cessation of the choreic movements is due to the same vascular change, pointing again to their dependance on some affection of the vaso-motor centre.

4. The effects of treatment.-It is beyond doubt that the removal of a palpable source of irritation may be followed by speedy cessation of chorea. In all such cases it is probable that the result is due to a decided lowering of the blood-pressure-i.e., to a change originating in the vaso-motor centre. Chorea has also yielded to large doses of chloral. In a wellknown case which occurred in Glasgow a choreic patient took sixty grains of chloral, profound sleep verging on coma being induced; but with awakening there was no return of the chorea. In another case, which also occurred in Glasgow, thirty grains procured the removal of the disease. Several instances have also been recorded where chloroform narcosis brought the affection to an end. That these drugs influence the vascular system is well known. According to Whitla, the action of chloral is directed against the vaso-motor centre, and brings about a fall in the blood-pressure. Sir Thomas Watson records a case where chorea was checked by sudden fright. That in such circumstances the vascular system is strongly affected is in the experience of everyone. The

12 Heart and Bloodvessels in the Young, A. Jacobi, p. 5. results which have been recorded by Professor M'Call Anderson and others from the treatment of chorea by anti pyrin point, I think, in the same direction-viz., that irregular vascular action is mainly concerned in the causation of chorea, as also of migraine (against which antipyrin is so potent); the consequent phenomena in each case being determined by the greater or less predisposition of certain. cerebral centres, motor, sensory, or psychical, to take on abnormal action.

5. Post-mortem evidence.-Dr. Dickinson's investigations go to prove the profound implication of the vascular system in fatal cases of chorea. His comparison of the disease to diabetes loses somewhat of its singularity on the above supposition.

6. The exciting causes of chorca. - If it be true that fright is by far the most common excitant of the disease, we have therein another argument for referring the phenomena of chorea to deranged action of the vaso-motor centre. It is highly improbable that its influence is directed against the motor cells, which some assert, as these are not likely re: cipients of sensory impressions. Through whatever centres such impressions are conducted, it is fair to assume that the resting point is the vaso-motor centre. And with regard to all other forms of irritation, it is just as easy to believe that they affect the same centre as that they act directly on the cells of the cortex cerebri.

Finally, as regards the relationship between chorea and rheumatism, it is to be borne in mind (1) that there is nothing improbable in the coincidence of the two affections (2) that rheumatism following chorea presents no diticulties when the sui generis nature of the former is considered (3) that chorea supervening on acute rheumatism (some other cause operating-e g, fright), just as it sometimes follows scarlatina or measles, or small-pox, may be explained by the unstable equilibrium of the nervous centres, including the vaso-motor centre, which is so apt to follow on febrilo disease, Whiflet, Scotland:

\section{ON CATARACT OPERATIONS:}

THE AFTER TREATMENT IN LIGHT ROOMS, AND BY AN ADHESIVE STRIP ON ONE EYE ONLY, THE EYE NOT OPERATED UPON BEING LEFT OPEN FOR THE COMFORT OF THE PATIENT. ${ }^{1}$

BY JULIAN J. CHYSOLM, M.D., BALTIMORE, U.S.A.

THE object of this paper is to give the results of my ex. periences in the after treatment of cataract extractions during the past four years. Up to that time it difered in no respect from that universally adopted. Indoctrinated early in the belief that movements of any kind were pre. judicial to an eye which had been freely opened for the removal of an opaque lens, I closed both eyes with care under compresses and bandages. I kept my patients on their backs in bed, and enjoined a passive state, with the avoidance of all unnecessary movements. Dark rooms were deemed an essential for successful treatment, and patients were secluded in them for two weeks. In other words, I carried out the universally restraining treatment without questioning its propriety.

All eye wards in hospitals have closed shutters to the windows, so that when cataract cases were under treatment all daylight could be excluded. In these black wards candles were necessary both for the convenience of attendants and for the professional visit. In the last few years a decided change has taken place in this regard. In many eye wards the inner shutters are no longer closed. The hoavy com presses which still cover the eyes of the patients exclude all light. They are not affected by the admission of daylight, while the service is in every way benefited. There are a few over-cautious surgeons who still use dark rooms and candle service. They will be forced to yield to a more enlightened experience. Four years since I found one of my friends, Dr. Michel of St. Louis, using strips of adhe sive plaster as a substitute for the compresses and bandages. His patients seemed to experience no bad results from the admission of a little light through the diaphanous material. He thought it more comfortable for his patients undergoing bed confinement not to have their International Medical Congress at Berlin. 
heads tied up. 'This was the old adhesive dressing of Desmarres, in general use by all eye surgeons prior to the introduction of chloroform, and before the vomiting which so often accompanies the administration of a general anscsthetic had exposed eyes operated upon to a new source of danger. When chloroform ancesthesia was accepted to prevent pain in cataract extractions, a more thorough protection of the wounded eye becamenecessary. Carefully adjusted compresses and bandages for the support of the eye against violent emesis was a potent item for safety during the after treatment. It was about this time, four years since, when cocaine, the local anæsthetic, had usurped the place of chloroform, and had therefore removed the dangerous element of vomiting during and after eye operations, that I found the strip of adhesive plaster in use by one of my friends. Under the new order of things, it appeared to me an especially good dressing, fultilling in every way the requirements for the quick and complete healing of the corneal wound. I therefore commenced a series of experiments in this direction.

After a smooth cataract extraction has been completed inspection of the eyeball shows the lips of the corneal wound to be in perfect apposition. The eyelids are then closed, the perfection of an adjustment of the wounded surfaces continuing. The cartilage of the upper lid makes a perfect natural splint for the cut cornea, and the orbicular muscle keeps up a constant tonic uniform pressure over the whole eye. We feel that if these conditions could be ensured for one week only the very best results would be obtained. I found that a piece of adhesive plaster secured the most desirable condition. When it was properly applied it kept the lids firmly together. It made no irregular pressure on the wounded eyeball. It caused no inconvenience, and it could not be displaced. These were very attractive features which the light dressing seemed to possess. After a careful trial it proved itself to be a great improvement over the compresses and bandages which I had been using since 1866. For the past four years I have substituted this light dressing for the heavy one, and am so perfectly satisfied with the results that $I$ would deem it a retrograde movement to go back to bandage eye dress. ings. Many ophthalmic surgeons have adopted this open dressing, as it is now called, at my suggestion, and they are enthusiastic in its praise. One application usually suffices for the entire treatment. If the slip is properly put on it will adhere firmly for one week, and a longer restraining treatment is not necessary after eye operations. The dressing consists of a piece of soft, salicylated, diaphanous, silk isinglass plaster, an inch and a half long by one inch wide. When the lids are closed after the completion of the operation, and the external surfaces moistened, the piece of plaster is laid upon the eye, extending from the upper edge of the superior tarsal cartilage to the chest. By a few strokes of the shell spoon it adjusts itself perfectly to the surfaces covered. Every lash is smoothed down and can be seen through the plaster, which covers nearly the whole width of the lid, leaving only the canthi exposed. Any excess of moisture is absorbed by the careful pressure of a soft towel. In a very fer minutes the plaster dries. This light-coloured, flexible, silk isinglass plaster is prepared by Seabury and Johnson of New York, and can be had of Messrs. Weiss, instrument makers, of London, and becomes a permanent fixture. Through it the condition of the lids can be daily seen, and the character of the eye secretinns examined, without removing the dressing. Medicated drops can find their way into the eye at the canthi, and the eye secretions can escape without detaching the plaster strip sufficiently to impair its efficiency. The perfect support given to the eyeball, without making the least irregularity in the pressure upon the eye surfaces, regardless of the movements of the wounded organ or of the head, can be obtained by no other application. Those who will use the adhesive plaster will now, nnder cocaine anesthesia, find it an immense advance in the direction of a more perfect eye dressing. From its simplicity and its efficiency it must eventually supersede compresses and bandages after the most delicate eye operations for cataract extractions and iridectomies.

My next step in the direction of an advanced treatment was in the doing away with bed confinement. With the eye properly and permanentlv closed by converting the two lids, as it were, into one undivided septum, the perfect and constant support secured to every part of the eyeball ensures no disturbance of the lips of the wound, it matters not in which position the patient is put, whether on his back, his side, or his feet. This valuable dressing, in my experience, has also proved itself a luxury, as it has virtually allowed me to do away with all bodily restraints. The confinement in bed is an annoyance to many which it is well to avoid, if it can be done without danger. I found after close observation that the sitting up or the lying down under this dressing had no effect upon the condition of the eyeball, therefore, I no longer restrain cataract patients to the supine position. If inmediately after the operation they prefer to sit in a chair rather than to recline upon the bed I can, without detriment to the eye, allow them to follow their own inclination. From my present standpoint of four years' experience in several hundred cataract ex. tractions and iridectomies I deem bed confinement, especially with patients lying compulsorily on their backs, a needless precaution, often annoying and at times injurious. In the light rooms in which 1 now treat my eye cases an appreciable amount of light is transmitted to the eye through the diaphanous adhesive plaster. In the very early days of my experiments I found this not disadvantageous. The eyes, not absolutely in the dark, did not become as sensitive as when all lignt was excluded. I also observed that when, through stiffiness of the eyelashes, or owing to the escape of an excess of eye secretions, the lash border was loosened a little from the adhesive covering, so that light could stray in to one or both eyes through the partially opened palpebral split, the eyes, when finally exposed by the permanent removal of the dressing, looked rather the better. They were less red, less watery, and less sensitive to light. This has been so often observed that now in cases of very heavy, stiff eyelashes, after the dressing is dry, when the patient remarks that he can clearly see the light through a crevase made by the slight separation of the lids, I still consider the strap well applied, and in such eases no longer attempt to close the lids more perfectly. It needs much faith on the part of anxious nervous patients to go through the very long week of blindfolding, counting the days, hours, and minutes before liberation when they hope to see. Bad enough as this is in those blind in each eye, it is vastly more so to those who still possess a useful eye. This confinement often deters a timid person from undergoing an operation for the restoration of sight. Knowing that a clean corneal wound will heal as rapidly as do wounds in any other part of the body, I became convinced that the eye not operated upon could be released, without detriment to the eye operated upon, at a much earlier stage of treatment than I had been in the habit of doing. It would often release the good eye when only one half of the confinement treatment for the one uperated upon had been passed. This question finally presented itself to me for serious consideration. Was there really any advantage gained to the patient by the universal custom of closing the eye not operated upon, if the other be well supported? And if not, what an immense advantage the patient would secure by having it left open. An every. day experience with the adhesive dressing had convinced me that the corneal wound was so perfectly supported and protected by it that no rotation of the eyeball would disturb it. I was disposed to believe that this protection would be continued even when free movements were permitted in the eye not operated upon. This, my next and most important modification in the after treatment of cataract extraction, was one that could only come from the courage of one's convictions. It was a direct attack upon the universally accepted belief that the movements of one eye necessarily imparted to the other must do injury to the eye operated upon, and that, therefore, both eyes must be kept quiet and necessarily closed.

After a smooth extraction with iridectomy, in a case of simple senile cataract in a healthy man of phlegmatic temperament, in every way a suitable case for the procedure, I made bold to leave the useful eye open, closing only the one operated upon with the adhesive strip. Regardless of the position of the eyeball in its rotatory movements, I believed that this light dressing would make no irregular pressure, and therefore cause no gaping of the corneal wound. I watched the course of this novel treatment with anxiety, knowing that I was going contrary to what was deemed most important by every eye surgeon. Fortu. nately for suffering humanity the case progressed as smoothly as if the most restraining treatment in bed, with both eyes bandaged, had been carefully carried out. The 
final result was so perfect that I was induced to repeat the experiment in a number of cases until $I$ was forced to the conclusion that $I$ had needlessly restrained a great many patients to their discomfort.

Now I never close the eye not operated upon. My cataract patients are not restricted in seeing by undergoing an operation for cataract extraction. The sight which they had the day before the operation they continue to enjoy during the entire treatment. This revolutionary act in eye dressing has not only proved itself of immense comfort to the invalid, but has actually added materially to the rapidity of the convalescence; so that now I am able to liberate the eye operated upon as early as the fifth day, and in many cases have done so on the fourth. In one or two cases in which the adhesive strip had become detached prematurely at the end of the third day after operation, I found the corneal wound so perfectly healed that I did not reclose the eye. I now in cataract extractions leave the seeing eye open with the same confidence that I formerly had when I securely closed it up. An experience of over 400 cataract extractions has given ne conclusive evidence that by this course of treatment I not only do the eye operated upon no harm, but, on the contrary, positive good. However forcibly we may theorise on this subject, the fact still remains that, in my experience, the movements of the exposed eye do not disturb injuriously the cut one. The corneal wound heals quite as promptly as when both eyes are shut. I have also found that the eye operated upon, and closed only by a diaphanous strip, has its final healing much advanced when, through the whole treatment, the other eye is exposed to moderate light. Neither eye then becomes over-sensitive, as when the dark treatment is followed. When the adhesive dressing is removed, on the fourth or fifth day, the eye operated upon will be found much less red, watery, and sensitive than when closely confined by heavy coverings. Convalescence, as a rule, will be so rapid that ten days after the operation patients can walk about tha house without inconvenience from the light and without the desire for the protection of smoked glasses.

For the past two years I have operated upon all simple senile cataracts without iridectomy. I clean the anterior chamber as carefully as possible, and replace the iris so as to establish a round well-contracted pupil, with the lips of the corneal wound thoroughly adapter. A few drops of an eserine solution half per cent. strength are instilled into the eye operated upon. Both eyes are temporarily closed for the adjustment of the adhesive strip over the lids of the one operated upon. As soon as it dries it holds the lids very securely together. The patient is then told to open the other eye. The patient gets out of the operating chair, and, if he has sight enough in the exposed eye, walks unaided from the operating room to his chamber. He reclines on the sofa, sits upon or lies upon the bed at will. He eats his regular meals. At bed time he undresses himself, and unaided makes his own toilet in the morning. He walks about the room, escapes the annoyance of being fed by the nurse, receives the visits of his friends, and in many respects is unrestrained in his movements. The diaphanous character of the dressing admits of the daily inspection of the lids. If no excessive discharge appears, there can be no trouble going on, and the dressing is not disturbed. As an additional security for pupillary shrinkage I instill at bedtime, on the day of operation, a drop of the eserine solution. It finds its way from the inner canthus under the plaster, and by capillary action gets on the cornea. This ensures the removal of the iris from the corneal wound, and tends to prevent prolapse. On the fourth or fifth day, when the adhesive strip is finally removed, I use locally atropia to expand the pupil. I remove the adhe. sive strip by detaching a corner and pulling the whole dressing off dry. Should the patient complain of the traction, the lids are moistened, when the adhesive piece comes off without effort. The eyelids are then cleansed of adherent secretions with warm water. The daylight of the room permits of a perfect examination of the eye. The corneal wound is found healed and the eye much less congested than when treated by the old method with heavy compresses, a proof that much of the irritability of the eyes, as seen after the usual method of dressing cataract cases, should be charged to the exclusion of light and not to the corneal wound. When the adhesive plaster has been removed on the fourth or fifth day the newly exposed eye needs no further protection. The eye not operated upon and never closed had all along accommodated itself to the moderate light of the sick chamber, from which only sunlight had been excluded; and the newly exposed eye, on account of the previous exposure of its companion, speedily does the same. In two weeks after operation the period at which cataract patients usually leave the hospital, very few need the protection of smoked glasses on going out upon the street. The majority go out without them. Prior to four years ago every eye operated upon and treated in the then dark wards of the hospital had to be supplied with smoked glasses, which the hospital authorities purchased by the gross. On account of the change made in the eye dressing, smoked glasses are no longer an article of hospital purchase.

In conclusion, I would say that my experience of the past four years in several hundreds of cataract and iridectomy cases has shown conclusively to myself and to a large number of professional friends who have adopted my methods that the leaving of one eye open for the comfort of the patient in no way detracts from the final success of the operation. Also that treatment in a moderately lighted room is conducive to a more rapid convalescence. Also that freedom from restraint and the varied movements of the patient have in no instance in my knowledge endangered the very large percentage of cures which we all individually are carefully studying to secure. In drawing attention to these radical changes in the after treatment of cataract extractions and other eye operations, I know that I am acting safely when I advise a trial of this new line of treatment, feeling assured that personal experiences, regardless of preconceived theories, will lead to the adoption of this better and more advanced method of treating cataract patients.

\section{INFLUENZA : ITS CLINICO-PATHOLOGICAL ASPECT.}

\section{By THOS. GLOVER LYON, M.A., M.D. CANTAB.,} ASSISTANT PHYSICIAN, VICTORIA-PARK HOSPITAL.

INFLUENZA, like all similar diseases, is viewed from three standpoints-that of the medical officer of health, of the pathologist, and of the practical physician. Under the first two heads probably nothing has been learnt from the late epidemic. The sanitary officer has failed to arrest its advance, or even to determine its mode of progression. The labours of the post-mortem examiner to detect any specific lesion in its victims, and of the bacteriologist to discover the ultimate cause of the disease, have been equally fruitless. When, however, we regard the disease from the practical physician's, or from what may be called the clinicopathological, point of view, the case is quite different; the late experience has largely modified the opinions concerning influenza generally held, as far as this department of medicine is concerned. Although the list of symptoms handed down to us from former epidemics will serve perfectly well for the late one, they were arranged in such a manner that a month or more passed after the beginning of the visitation before the presence of the disease amongst us was universally acknowledged. The cause of this was not far to seek, for the disease was described as being chiefly incident upon the respiratory tract; in fact, observers were on the look out for a disease of the nature of a bad cold attended with an unnsual amount of depression. The object of the following remarks is to show that the poison of influenza attacks chiefly the central nervous system, and that the damaged state of this tract is impressed upon all the phenomena observed in this interesting disease, and constitutes a connecting link between them. The importance of determining the parts of greatest incidence of a disease need not be insisted upon.

In a letter to Dr. Sisley, Professor Proust writes: "D'ailleurs les divers synıtômes observés dans la grippe révèlent bien plus tôt un trouble nerveux général qu'un état d'inflammation franche."

1. The simplest form of the disease displays itself as follows: The patient suddenly finds himself incapable in mind and body; he is unable, except with the utmost exertion, to finish anything he may be doing, the slightest effort being followed by an extreme feeling of fatigue. Within a few hours follow intense pain at the back of the 